\title{
Loss of mural cell-derived laminin aggravates hemorrhagic brain injury
}

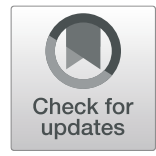

Jyoti Gautam, Lingling Xu, Abhijit Nirwane, Benjamin Nguyen and Yao Yao*

\begin{abstract}
Background: Mural cells synthesize and deposit laminin to the basement membrane. To investigate the function of mural cell-derived laminin, we generated a mutant mouse line lacking mural cell-derived laminin (termed PKO). In a previous study, we showed that the PKO mice were grossly normal under homeostatic condition, but developed blood-brain barrier (BBB) breakdown with advanced age ( $>8$ months), suggesting that these mutants are intrinsically weak. Based on these findings, we hypothesized that PKO mice have exacerbated injuries in pathological conditions.

Methods: Using collagenase-induced intracerebral hemorrhage $(\mathrm{ICH})$ as an injury model, we examined various stroke outcomes, including hematoma volume, neurological function, neuronal death, BBB integrity, paracellular/ transcellular transport, inflammatory cell infiltration, and brain water content, in PKO mice and their wildtype littermates at young age (6-8 weeks). In addition, transmission electron microscopy (TEM) analysis and an in vitro $\mathrm{ICH}$ model were used to investigate the underlying molecular mechanisms.

Results: Compared to age-matched wildtype littermates, PKO mice display aggravated stroke outcomes, including larger hematoma size, worse neurological function, increased neuronal cell death, enhanced BBB permeability, increased transcytosis, and elevated inflammatory cell infiltration. These mutants also exhibit high baseline brain water content independent of aquaporin-4 (AQP4). In addition, mural cell-derived laminin significantly reduced caveolin-1 without affecting tight junction proteins in the in vitro ICH model.
\end{abstract}

Conclusions: These results suggest that mural cell-derived laminin attenuates BBB damage in ICH via decreasing caveolin-1 and thus transcytosis, regulates brain water homeostasis, and plays a beneficial role in $\mathrm{ICH}$.

Keywords: Intracerebral hemorrhage, Blood-brain barrier, Mural cells, Edema, Laminin

\section{Background}

Stroke is a leading cause of death and long-term disability in the USA $[1,2]$. Although ICH accounts for only $10-15 \%$ of all strokes, it has extremely high mortality and disability rates and there is no effective treatment for this devastating disease so far $[1,3]$. Emerging evidence suggests that the neurovascular unit plays an important role in stroke pathogenesis $[4,5]$. The neurovascular unit consists of many different cell types and a non-cellular component-the

\footnotetext{
* Correspondence: yyao@uga.edu

Department of Pharmaceutical and Biomedical Sciences, University of Georgia, 240 W Green Street, Athens, GA 30602, USA
}

basement membrane (BM) [6-8]. By interacting with different cell types via integrins and other receptors, the BM contributes to the structural and functional integrity of the neurovascular unit $[9,10]$. It has been reported that integrin expression is substantially altered after stroke and integrins play an important role in stroke pathogenesis $[9,11-13]$. Compared to integrins, the BM is relatively understudied. Although BM dissolution is observed after stroke, how each $B M$ component changes in stroke is controversial $[6,9,14]$. In addition, the function of $\mathrm{BM}$ in the pathogenesis of stroke remains largely unknown.

Laminin, a trimeric protein composed of $\alpha, \beta$, and $\gamma$ subunits is the only constituent required for $\mathrm{BM}$

(c) The Author(s). 2020 Open Access This article is licensed under a Creative Commons Attribution 4.0 International License, which permits use, sharing, adaptation, distribution and reproduction in any medium or format, as long as you give appropriate credit to the original author(s) and the source, provide a link to the Creative Commons licence, and indicate if changes were made. The images or other third party material in this article are included in the article's Creative Commons licence, unless indicated otherwise in a credit line to the material. If material is not included in the article's Creative Commons licence and your intended use is not permitted by statutory regulation or exceeds the permitted use, you will need to obtain permission directly from the copyright holder. To view a copy of this licence, visit http://creativecommons.org/licenses/by/4.0/ The Creative Commons Public Domain Dedication waiver (http://creativecommons.org/publicdomain/zero/1.0/) applies to the data made available in this article, unless otherwise stated in a credit line to the data. 
assembly $[9,15,16]$. So far, five $\alpha$, four $\beta$, and three $\gamma$ genetic variants have been identified $[9,15,16]$. Different combinations of these subunits generate a large number of laminin isoforms. However, only 20 isoforms have been identified or proposed based on experimental data $[9,15,17]$. At the neurovascular unit, laminin is mainly synthesized by astrocytes, brain microvascular endothelial cells (BMECs), and pericytes [9]. Interestingly, these cells make different laminin isoforms. For example, astrocytes generate laminin- $\alpha 2 \beta 1 \gamma 1 \quad(-211) \quad[9,18-20]$, BMECs mainly make laminin- $\alpha 4 \beta 1 \gamma 1(-411)$ and $-\alpha 5 \beta 1 \gamma 1(-511)$ $[9,21-23]$, while pericytes predominantly synthesize $\alpha 4 /$ $\alpha 5-$ and $\gamma 1$-containing laminins $[9,24]$. Located at the interface of the circulation system and the CNS $[9,15]$, laminin is well positioned to regulate BBB permeability.

Using conditional knockout mice and adenovirus expressing Cre under GFAP promoter, we have shown that loss of astrocytic laminin leads to BBB breakdown and agedependent ICH $[20,25]$. Echoed with this finding, laminin$\alpha 2^{-/-}$mice show BBB disruption [19]. These results suggest an indispensable role of astrocytic laminin (laminin-211) in BBB maintenance under homeostatic condition. Using endothelium-specific laminin- $\alpha 5$ knockout mice, we and others have demonstrated that endothelial laminin- $\alpha 5$ is dispensable for $\mathrm{BBB}$ maintenance under homeostatic condition but promotes BBB recovery after $\mathrm{ICH}[26,27]$.

To investigate the function of pericyte-derived laminin in BBB maintenance, we generated a mural cell-specific conditional knockout mouse line (laminin- $\gamma 1^{\text {flox/flox }}$ : PDGFR $\beta-\mathrm{Cre}^{+}$, termed PKO) by crossing the laminin- $\gamma 1$ floxed mice with the PDGFR $\beta$-Cre line. Laminin- $\gamma 1$ was chosen for the following two reasons: (1) among all three $\gamma$ subunits, laminin- $\gamma 1$ is highly expressed in pericytes $[9,24,28]$ and (2) pericytes mainly express $\alpha 4 / \alpha 5$ - and $\gamma 1$-containing laminins, and ablating laminin- $\gamma 1$ leads to loss of both laminin- $\alpha 4$ and laminin- $\alpha 5$ in pericytes [28]. Under C57Bl6-FVB mixed background, these PKO mutants display hydrocephalus and BBB breakdown with incomplete penetrance [24]. To determine whether the $\mathrm{BBB}$ disruption phenotype is due to loss of mural cellderived laminin or secondary to hydrocephalus, which can compromise $\mathrm{BBB}$ integrity, we crossed the $\mathrm{PKO}$ mice into C57Bl6 dominant background, in which they fail to develop hydrocephalus [28]. Under C57Bl6 dominant background, the PKO mice have intact $\mathrm{BBB}$ integrity at young age $(<4$ months $)$ and develop mild BBB compromise at old age (8-15 months) [28], possibly due to diminished compensation by other laminin isoforms at old age. These results suggest that mural cell-derived laminin also contributes to $\mathrm{BBB}$ maintenance but to a lesser extent.

We reason that, in conditions with compromised laminin compensation (e.g., increased laminin degradation), the PKO mice will show exacerbated outcomes even at young age. Here, we tested this hypothesis using $\mathrm{ICH}$ as a model, where laminin levels are significantly reduced [6].

\section{Materials and methods \\ Animals}

Laminin- $\gamma 1^{\text {flox/flox }}$ mice were crossed with the PDGFR $\beta$ $\mathrm{Cre}^{+}$line to generate PKO (laminin- $\gamma 1^{\text {flox/flox }}$ :Pdgfr $\beta-\mathrm{Cre}^{+}$) mice. Laminin- $\gamma 1^{\text {flox/flox }}$ mice and heterozygotes (laminin$\gamma 1^{\text {flox/+ }}:$ Pdgfr $\left.\beta-\mathrm{Cre}^{+}\right)$were used as littermate controls for PKO mice. All mice were maintained in C57Bl6 dominant background and mice of both genders at $6-8$ weeks old were used in this study. The validation and characterization of the PKO mice were reported in previous studies [24,29]. All mice were maintained in the animal facility at the University of Georgia with free access to water and food. Experimental procedures were conducted in accordance with the NIH guide for care and use of animals and were approved by the Institutional Animal Care and Use Committee (IACUC) at the University of Georgia. Experiments were conducted and reported per the ARRIVE guidelines.

\section{$\mathrm{ICH}$ model}

Control and PKO mice were anesthetized by intraperitoneal injection of avertin $(500 \mathrm{mg} / \mathrm{kg}$ of body weight) and placed on the stereotaxic frame (Stoelting Co., IL, USA). Through a hole drilled in the skull, collagenase (type VIIS; Sigma, St. Louis, USA; $0.15 \mathrm{U}$ in $0.7 \mu \mathrm{l}$ saline) was injected into the striatum $(0.2 \mathrm{~mm}$ posterior to bregma, $2.4 \mathrm{~mm}$ lateral from the midline, and $3.7 \mathrm{~mm}$ in depth) using a $1-\mu \mathrm{l}$ syringe (Hamilton) controlled by a stereotaxic instrument over $5 \mathrm{~min}$. After injection, the needle was kept in place for $10 \mathrm{~min}$ to prevent reflux. Mice injected with equal amount of saline were used as sham controls. At various time points after injury, mice were transcardially perfused with either PBS or PBS followed by $4 \%$ paraformaldehyde (PFA) [30-35]. For the former, the brains were frozen in dry ice, cryosectioned, and stored at - $80^{\circ} \mathrm{C}$. For the latter, the brains were post-fixed in $4 \%$ PFA overnight at $4{ }^{\circ} \mathrm{C}$, immersed in $30 \%$ sucrose solution for $24 \mathrm{~h}$, cryosectioned, and stored at $-80^{\circ} \mathrm{C}$.

\section{Neurological deficit}

Mice were scored for neurological deficits at various time points after injury using a modified scoring system [30, 31, 36]. In this system, six properties (body symmetry, gait, climbing, circling behavior, front limb symmetry, and compulsory circling) were graded from 0 to 4 , establishing a maximum score of 24 . Higher scores indicate more severe neurological deficits. Investigators performing this test were blinded to the genotype of mice.

\section{Histology}

Hematoxylin staining was performed as described previously [30-32]. Briefly, sections were washed twice in PBS 
and kept in hematoxylin for $15 \mathrm{~min}$ at room temperature. After two washes in tap water, the sections were incubated in $70 \%$ ethanol with $1 \%$ hydrochloric acid for $3 \mathrm{~s}$, followed by three washes in tap water. Then, the sections were dehydrated in graded alcohol $(70 \%, 80 \%, 90 \%, 100 \%$, and $100 \%)$, cleared in xylene, and mounted with DPX. Images were taken under a Nikon Eclipse Ti microscope. Hematoma size was quantified using serial coronal sections as described previously [30, 36]. Briefly, 20- $\mu \mathrm{m}$-thick serial coronal sections were cut using a cryostat (Microm HM 550, Thermo Scientific, USA). Eight sections evenly distributed along the rostral-to-caudal axis were collected from each brain. Hematoma areas $\left(\mathrm{mm}^{2}\right)$ from serial coronal sections were added, and the injury volume $\left(\mathrm{mm}^{3}\right)$ was calculated as follows: injury volume $=$ measured area $\times$ section thickness.

Fluoro-Jade C (FJC) staining was performed using a standard protocol as described previously [30,37]. Briefly, sections were incubated in $1 \% \mathrm{NaOH}$ in $80 \%$ ethanol for $5 \mathrm{~min}$, washed in $70 \%$ ethanol and distilled water, and incubated in $0.06 \% \mathrm{KMnO}_{4}$ for $10 \mathrm{~min}$. After extensive washes in water, the sections were transferred to $0.0001 \%$ FJC (in $0.1 \%$ acetic acid) for $10 \mathrm{~min}$. Then, the sections were rinsed in water, dried at $56{ }^{\circ} \mathrm{C}$, cleared in xylene, and mounted with DPX. Images were taken from peri-hematoma regions using a Nikon Eclipse Ti microscope. FJC ${ }^{+}$cells were counted in six to eight sections (three fields/section) immediately adjacent to the hematoma as described previously [30-32]. At least three animals/group/time point were used for quantification.

\section{Immunohistochemistry}

Brain sections were fixed in 4\% PFA for $15 \mathrm{~min}$. After extensive washes with PBS, the sections were incubated in blocking buffer (1 \% BSA in PBS containing 0.3\% normal donkey serum and $0.3 \%$ Triton X-100) for $1 \mathrm{~h}$ at room temperature. Next, the sections were incubated with primary antibodies [rat-anti-CD31 (1:200, BD Biosciences, 553370), mouse anti-claudin-5 (1:200, Invitrogen, USA, 35-2500), rabbit anti-ZO-1 (1:400, Thermofisher, USA, 61-7300), rabbit anti-caveolin-1 (1:500, Cell Signaling, 3238S), rabbit anti-PDGFR $\beta$ (1:200, Cell Signaling, 3169), rabbit anti-AQP4 (1:500, Millipore, USA, AB3594), rat anti-Ly6G (1:200; Biolegend, USA, 108402), rat anti-CD3 (1:200, eBioscience, USA, 140032-82), rat anti-CD11b (1:200, BD Biosciences, 553309), mouse anti-glial fibrillary acidic protein (GFAP, 1:200, BD Bioscience, USA, 556327), and rabbit anti-Iba1 (1:500; Wako Inc, USA, 019-19741)] overnight at $4{ }^{\circ} \mathrm{C}$. After extensive washes, the sections were incubated with appropriate fluorescent secondary antibodies. After extensive washes, the sections were mounted with fluoromount-G with DAPI. Images were taken from peri-hematoma regions using a Nikon Eclipse Ti microscope or LSM710 confocal microscope.

\section{Image analyses}

For claudin-5/ZO-1 coverage, claudin-5-, ZO-1-, and CD31positive fluorescent areas were determined using the ImageJ area measurement tool. Claudin-5/ZO-1 coverage was determined as the percentage (\%) of claudin-5/ZO-1-positive fluorescent area covering CD31-positive capillary area. Average claudin $5 / \mathrm{ZO}-1$ length was determined by measuring the length of claudin $5^{+}$and $\mathrm{ZO}-1^{+}$vessels using the $\mathrm{NIH}$ ImageJ "Neuro J" plug-in length analysis tool. For pericyte coverage, PDGFR $\beta$ - and CD31-positive fluorescent areas were determined using the ImageJ area measurement tool. Pericyte coverage was determined as the percentage (\%) of PDGFR $\beta$ positive fluorescent area covering CD31-positive capillary area, as previously described [38]. For AQP4 coverage, $\mathrm{AQP} 4$ - and CD31-positive fluorescent areas were determined using the ImageJ area measurement tool. AQP4 coverage was determined as the percentage (\%) of AQP4positive fluorescent area covering CD31-positive capillary area. For caveolin-1 expression, mean fluorescence intensity was used. For inflammatory cell infiltration, total numbers of $\mathrm{Ly} 6 \mathrm{G}^{+} / \mathrm{CD}^{+} / \mathrm{CD} 11 \mathrm{~b}^{+}$cells were counted. For microglial number, Iba1 ${ }^{+}$cells were counted. For astrocyte activation, GFAP mean fluorescence intensity was used. For quantifications, three random fields from each section, 8 serial sections along the rostral-to-caudal axis for each brain, and 3-5 animals were used. All data analyses were performed on zprojection $(15-20 \mu \mathrm{m})$ images by a blinded investigator.

\section{Brain water content measurement}

Mice were euthanized and their brains were rapidly collected. The contralateral and ipsilateral hemispheres as well as cerebellum were used for analysis. After obtaining the wet weights using an analytical balance, collected tissues were dried for $24 \mathrm{~h}$ and weighed again (dry weight). Brain water content was calculated as follows: brain water content $=($ wet weight - dry weight $) /$ wet weight $\times 100[30,39]$.

\section{BBB permeability assay}

$\mathrm{BBB}$ permeability was examined using in vivo permeability assay as described previously [40, 41]. Briefly, sterile Evans blue solution ( $2 \%$ in saline, $80 \mu \mathrm{l})$ and FITC-Dextran $(4 \mathrm{kD}, 25 \mathrm{mg} / \mathrm{ml}, 50 \mu \mathrm{l})$ were injected intravenously into control and PKO mice. After $6 \mathrm{~h}$, these mice were transcardially perfused with $50 \mathrm{ml}$ saline. The brains were then collected and cut into left and right hemispheres. Each hemisphere was carefully weighed and homogenized in $800 \mu \mathrm{l}$ PBS and centrifuged at 16,363 g (Eppendorf FA-45-24-11 rotor) for $20 \mathrm{~min}$ at $4{ }^{\circ} \mathrm{C}$. For Evans blue, the supernatant was collected and read in a spectrophotometer (Molecular devices-SpectraMax, California, USA) at $620 \mathrm{~nm}$. For FITC-Dextran, the supernatant was collected and read in a fluorescent plate reader (Molecular devices-SpectraMax, California, USA) at 485/528 
$\mathrm{nm}$. Each sample was measured in triplicates, and the average of these technical replicates was used as one biological replicate.

\section{Transmission electron microscopy (TEM)}

Mice were anesthetized and perfused with PBS followed by $0.1-\mathrm{M}$ sodium cacodylate buffer containing $2 \%$ PFA and $2 \%$ glutaraldehyde. Brain tissue from the perihematoma zone was dissected out, fixed overnight, and post-fixed in $1 \%$ osmium tetroxide and $1 \% \mathrm{~K}$ ferrocyanide. Next, the tissue was en bloc stained with $2 \%$ uranyl acetate and embedded in resin. Ultra-thin sections were cut on an RMC MT-X microtome (Boeckeler Instruments) and post-stained with $2 \%$ uranyl acetate and $1 \%$ lead citrate. Sections were examined and photographed using JEOL JEM1011 (JEOL) at $80 \mathrm{kV}$.

\section{Cell culture}

Mouse brain endothelial cells (bEnd.3, CRL-2299), mouse bone marrow cells (LADMAC, CRL-2420), and mouse brain microglia (EOC 13.31, CRL-2468) were purchased from ATCC. bEnd.3 cells were cultured in standard medium [Dulbecco's modified Eagle's medium (DMEM) supplemented with $10 \%$ fetal bovine serum (FBS), 100 units $/ \mathrm{ml}$ penicillin and $100 \mu \mathrm{g} / \mathrm{ml}$ streptomycin]. LADMAC cells were cultured in Eagle's minimum essential medium (MEM) supplemented with 10\% FBS, 100 units/ $\mathrm{ml}$ penicillin, and $100 \mu \mathrm{g} / \mathrm{ml}$ streptomycin. EOC 13.31 cells were cultured in standard medium supplemented with 20\% LADMAC conditioned media. All cells were cultured at $37{ }^{\circ} \mathrm{C}$ under a $5 \% \mathrm{CO}_{2}$ atmosphere.

\section{In vitro ICH model}

The in vitro ICH model was established as described previously [42]. Briefly, EOC 13.31 cells were treated with $10-\mu \mathrm{M}$ hemoglobin for $24 \mathrm{~h}$ and the supernatant was collected as microglia-conditioned medium. When reached confluence, bEnd.3 cells were treated with the collected microgliaconditioned medium to mimic ICH in vitro. This experiment was performed in the presence or absence of $10 \mu \mathrm{g} / \mathrm{ml}$ laminin-421/-521 (Biolamina). After 24h, bEnd.3 cells were collected for western blot analysis.

\section{Western blotting}

Cells were lysed with RIPA buffer (50-mM Tris pH 7.4, 1\% NP-40, $0.5 \%$ Na-deoxycholate, $1 \%$ SDS, $150-\mathrm{mM} \mathrm{NaCl}, 2-$ mM EDTA, $1 \times$ protease inhibitor cocktail, and $1 \times$ phosphatase inhibitor cocktail). Total protein levels were determined using the Bio-Rad protein assay kit, and equal amounts of proteins were loaded and separated on SDS-PAGE. After transferring to PVDF membrane (Millipore), proteins were detected using a standard immune-blotting technique. The following primary antibodies were used: mouse anti-claudin- 5 (1:500, Invitrogen, USA, 35-2500), rabbit anti-ZO-1 (1:500,
Thermofisher, USA, 61-7300), rabbit anti-caveolin-1 (1:1000, cell signaling, 3238S), and mouse anti- $\beta$-actin (Sigma, A5441, 1:2000). Target proteins were visualized using SuperSignal West Pico Plus Chemiluminescent Substrate (Thermo scientific). The density of target protein bands was quantified using $\mathrm{NIH}$ ImageJ software. The expression of target proteins was normalized to that of $\beta$-actin.

\section{Statistics}

Prism 6 (GraphPad Software) was used to perform statistical analyses. Student's $t$ test was used to analyze differences between two groups. One-way ANOVA followed by Neuman Keuls post hoc analysis was used when more than two groups were compared. $p<0.05$ was considered to be significant. Sample number $(n)$ represents biological replicates. Sample sizes for experiments were shown in the figure legends. Results are shown as mean \pm SD.

\section{Results}

PKO mice show enlarged hematoma after ICH

Hematoma volume is one of the major determinants of mortality and morbidity in ICH outcomes [43]. Although no hematoma was found in sham animals, both control and PKO mice showed hematoma after ICH (Fig. 1a). Control mice showed a hematoma size of $10.01 \pm 2.91$ $\mathrm{mm}^{3}$ at day 2 after injury (Fig. 1a, b). Hematoma size remained similar at day 5 after injury $(11.39 \pm 0.81$ $\mathrm{mm}^{3}$ ) and substantially reduced by day 14 after injury $\left(5.41 \pm 0.83 \mathrm{~mm}^{3}\right)$ (Fig. 1a, b). Although a similar trend was observed in PKO mice, these mutants displayed increased hematoma volume at all three time points (16.14 $\pm 4.96 \mathrm{~mm}^{3}, 18.59 \pm 2.80 \mathrm{~mm}^{3}, 7.22 \pm 3.27 \mathrm{~mm}^{3}$ ) compared to the controls (Fig. 1a, b). Statistical significance, however, was only achieved at day 2 and day 5 after injury. These results suggest that mural cell-derived laminin negatively regulates hematoma size.

\section{PKO mice show worse neurological function after ICH}

Focal neurological deficits occur after ICH $[44,45]$. To assess neurological function, we scored control and PKO mice at various time points after injury using a wellestablished scoring system [30, 36]. Sham animals, independent of genotypes, showed very low neurological deficit scores, suggesting normal neurological function (Fig. 1c). Consistent with previous reports [30, 36], control mice showed a high neurological deficit score at day 1 after injury $(9.80 \pm 3.46)$, which slowly decreased overtime (8.60 \pm $2.23,7.08 \pm 1.38,6.67 \pm 0.89,6.60 \pm 0.55,5.40 \pm 1.34$, and $5.40 \pm 1.95$ in day 2 , day 3 , day 5 , day 7 , day 10 , and day 14 , respectively) (Fig. 1c). Like in the controls, neurological deficit score decreased overtime after ICH in PKO mice (12.40 $\pm 2.53,12.73 \pm 2.91,9.93 \pm 2.76,9.29 \pm 3.10,8.40 \pm 4.39$, $7.00 \pm 3.74$, and $8.60 \pm 4.51$ in day 1 , day 2 , day 3 , day 5 , day 7 , day 10, and day 14, respectively) (Fig. 1c). Compared 

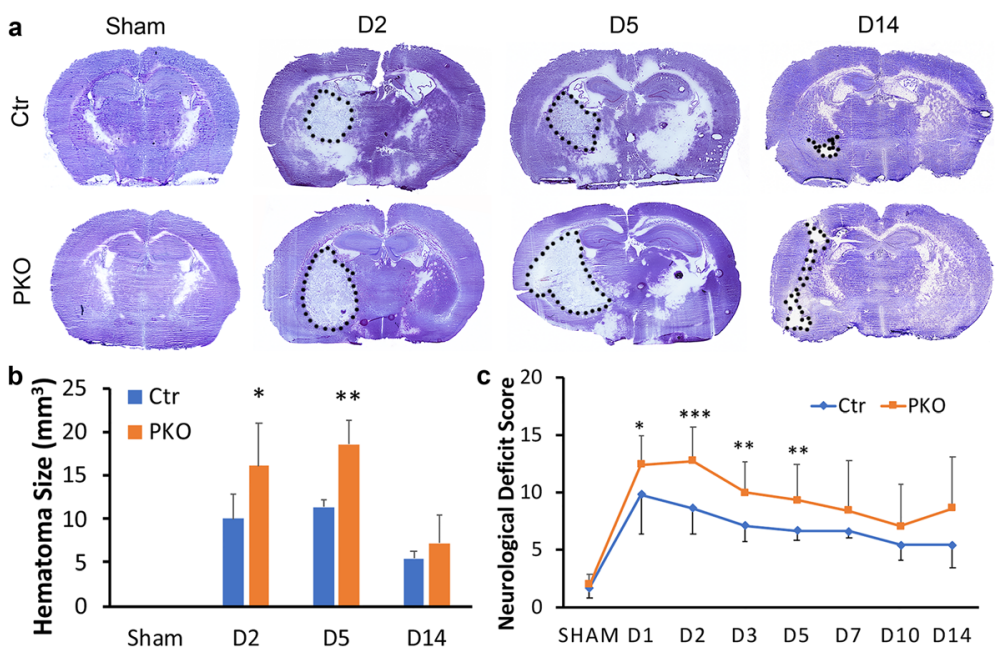

Fig. 1 PKO mice show enlarged hematoma size and increased neurological deficit score after ICH. a Representative images of hematoxylinstained control and PKO brains from sham group and at D2, D5, and D14 after ICH. Dashed lines mark injury areas. b Quantification of injury volume in control and PKO mice. ${ }^{*} p<0.05$ and ${ }^{* *} p<0.01$, compared to controls at the same time points (Student's $t$ test), $n=6$. c Neurological deficit score in control and PKO mice from sham group and at D1, D2, D3, D5, D7, D10, and D14 after ICH. ${ }^{*} p<0.05$ and ${ }^{* *} p<0.01,{ }^{* * *} p<0.001$, compared to controls at the same time points (Student's $t$ test), $n=5-15$ ( $n=15$ for D1-D2, $n=12-14$ for D3-D5, and $n=5$ for sham and D7D14). Data are shown as mean \pm SD

to the controls, the PKO mice displayed higher neurological deficit scores at all time points examined, although statistical significance was only achieved in early time points (up to day 5 after injury) (Fig. 1c). These findings suggest that mural cell-derived laminin plays a beneficial role in $\mathrm{ICH}$.

\section{PKO mice show enhanced neuronal death after ICH}

To determine if loss of mural cell-derived laminin affects neuronal death after $\mathrm{ICH}$, we performed FJC staining, which marks degenerating neurons [30, 37]. As expected, we failed to detect $\mathrm{FJC}^{+}$cells in sham animals independent of genotypes (Fig. 2a). Control (48.10 \pm 3.62) and PKO (48.40 \pm 7.22$)$ mice demonstrated comparable $\mathrm{FJC}^{+}$cells at day 2 after ICH (Fig. 2a, b). Compared to the controls, significantly more $\mathrm{FJC}^{+}$cells were found in PKO brains at day 5 (36.43 \pm 10.79 in control and 57.18 \pm 11.21 in PKO) but not day 14 (13.13 \pm 1.75 in control and $11.00 \pm 2.85$ in PKO) after injury (Fig. 2a, b), again suggesting aggravated injury in the mutants.

\section{PKO mice show exacerbated BBB disruption after ICH}

$\mathrm{BBB}$ disruption is a hallmark of $\mathrm{ICH}$-induced brain injury $[46,47]$. To determine BBB permeability, we intravenously injected 4kD-FITC-Dextran into control and PKO mice and examined its leakage into brain parenchyma at 2, 5, and 14 days after $\mathrm{ICH}$. Consistent with our previous finding that $\mathrm{BBB}$ integrity is intact in $\mathrm{PKO}$ mice at young age [28], FITC-Dextran leakage was not found in sham animals independent of genotypes (Fig. 2c). Although increased FITC-Dextran level was found in PKO brains at all three time points after $\mathrm{ICH}$, statistical significance was only achieved at day $2(48.28 \pm 10.36$ in control and 73.25 \pm 17.06 in $\mathrm{PKO}$ ) after injury (Fig. 2c). To determine the extent of BBB disruption, Evans blue, which serves as a $66 \mathrm{kD}$ tracer due to albumin binding, was also used. Again, no leakage of Evan blue was detected in sham animals (Fig. 2d). Similar to FITC-Dextran, a significantly higher level of Evan blue was found in PKO brains $(1.67 \pm 0.90)$ at day 2 after injury compared to the controls $(0.75 \pm$ 0.29) (Fig. 2d). Although a trend was detected at day 5 and day 14 after injury, statistical significance was not reached at these time points. These findings suggest that mural cell-derived laminin contributes to BBB recovery at early stage after $\mathrm{ICH}$.

\section{Loss of mural cell-derived laminin does not affect paracellular transport after ICH}

Tight junction proteins (TJPs) play an important role in maintaining paracellular barrier of the BBB [48-50]. To determine if decreased TJP is responsible for the enhanced $\mathrm{BBB}$ disruption in $\mathrm{PKO}$ mice after $\mathrm{ICH}$, we performed costaining of vascular marker CD31 and two TJPs (claudin-5 and ZO-1). Consistent with our previous finding that TJP expression is unaffected in PKO mice at young age [28], sham mice showed comparable and high levels of claudin5 coverage between genotypes $(87.35 \pm 9.31$ for control and $84.45 \pm 16.20$ for PKO) (Fig. 3a, b). After ICH, control mice demonstrated reduced claudin-5 coverage at day 2 $(61.76 \pm 11.56)$, day $5(60.81 \pm 11.53)$, and day $14(80.49 \pm$ 13.23) (Fig. 3a, b). Similar changes on claudin-5 coverage were observed in PKO mice at day 2 (67.04 \pm 16.81$)$, day 5 $(56.33 \pm 10.13)$, and day $14(80.55 \pm 15.54)$ after injury 


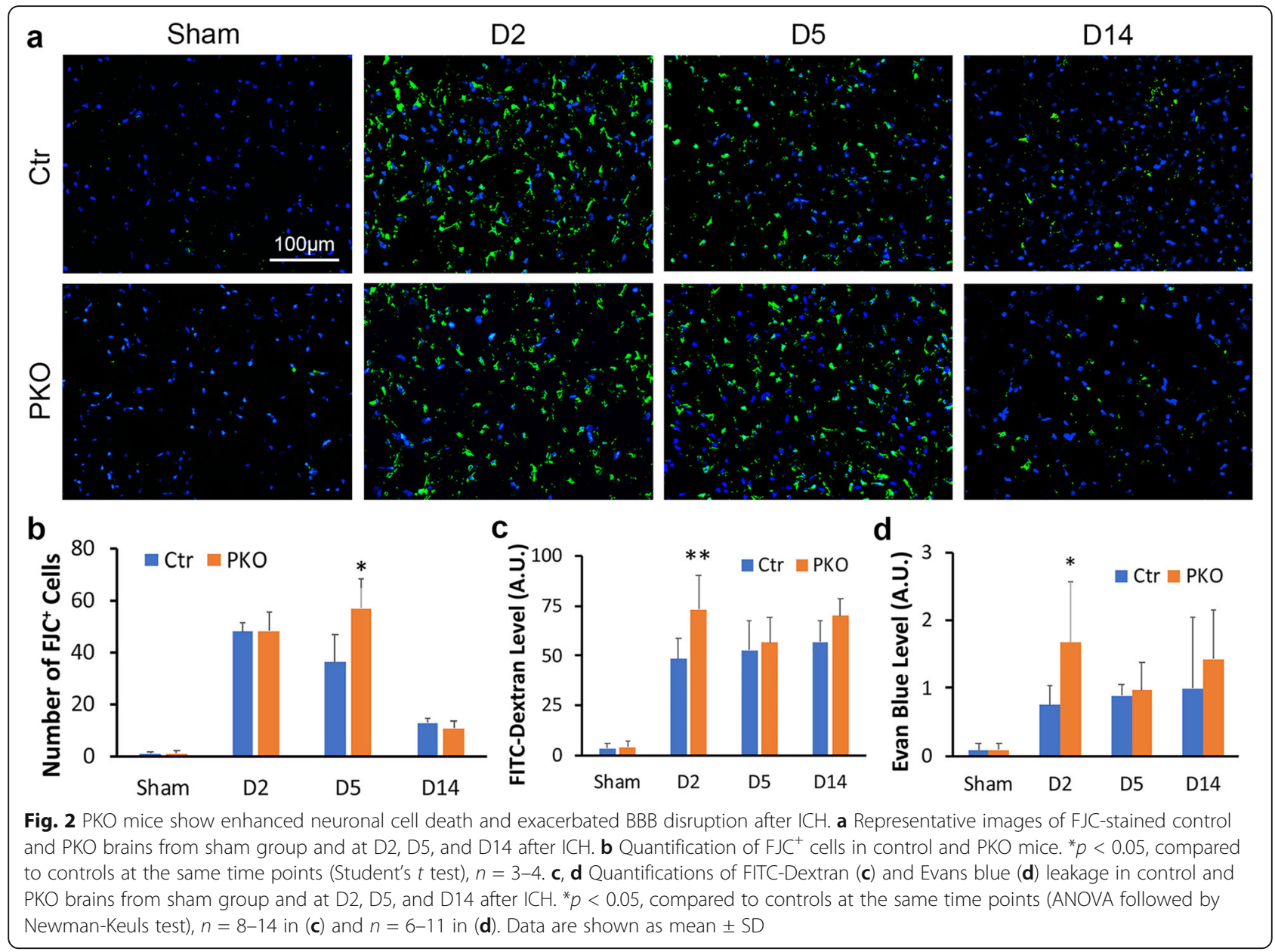

(Fig. 3a, b). Comparison between genotypes, however, failed to reveal statistical significance at any time point (Fig. 3b). In addition to claudin-5 coverage, we also quantified average claudin-5 length (Fig. 3c) between genotypes and found no statistical significance.

Like claudin-5, ZO-1 displayed high coverage in sham mice $(83.46 \pm 12.89$ for control and $78.09 \pm 9.76$ for PKO) (Fig. 3d, e). After ICH, ZO-1 coverage decreased in both control $(64.67 \pm 12.14,65.43 \pm 18.22$, and 80.84 \pm 7.37 at day 2 , day 5 , and day 14 after injury, respectively) and PKO (64.12 $\pm 15.84,79.78 \pm 13.61$, and 72.55 \pm 10.85 at day 2 , day 5 , and day 14 after injury, respectively) mice (Fig. 3d, e). No statistical significance was detected between genotypes (Fig. 3e). Similarly, average ZO-1 length (Fig. 3f) failed to show a significant difference between genotypes at any time point.

Next, we further examined the morphology of tight junctions at the ultrastructural level using TEM. In sham animals, both genotypes displayed nicely aligned electron-dense tight junctions at cell-cell borders (Fig. 4). After $\mathrm{ICH}$, tight junctions became irregular, detached, or even lost in some regions (Fig. 4a).
Comparison between genotypes, however, failed to reveal any difference (Fig. 4a). Together, these findings suggest that mural cell-derived laminin does not affect paracellular transport in endothelial cells after ICH.

\section{Loss of mural cell-derived laminin increases transcellular transport after ICH}

In addition to intercellular tight junctions, extremely low transcellular transport also contributes to BBB integrity [51-53]. To determine if increased transcellular transport is responsible for the enhanced $\mathrm{BBB}$ leakage in $\mathrm{PKO}$ mice after $\mathrm{ICH}$, we examined transcytosis by TEM. In sham controls, few pinocytotic vesicles and a thin layer of basement membrane (BM) were observed independent of the genotypes (Fig. 4a), indicating unaltered transcellular transport in PKO brains under homeostatic conditions. After $\mathrm{ICH}$, we observed swollen astrocytic endfeet and thickened BM in both genotypes (Fig. 4a), indicating successful induction of injury. Interestingly, significantly more endothelial pinocytotic vesicles were found in PKO mice at day 2 and day 5 after $\mathrm{ICH}$, compared to the 

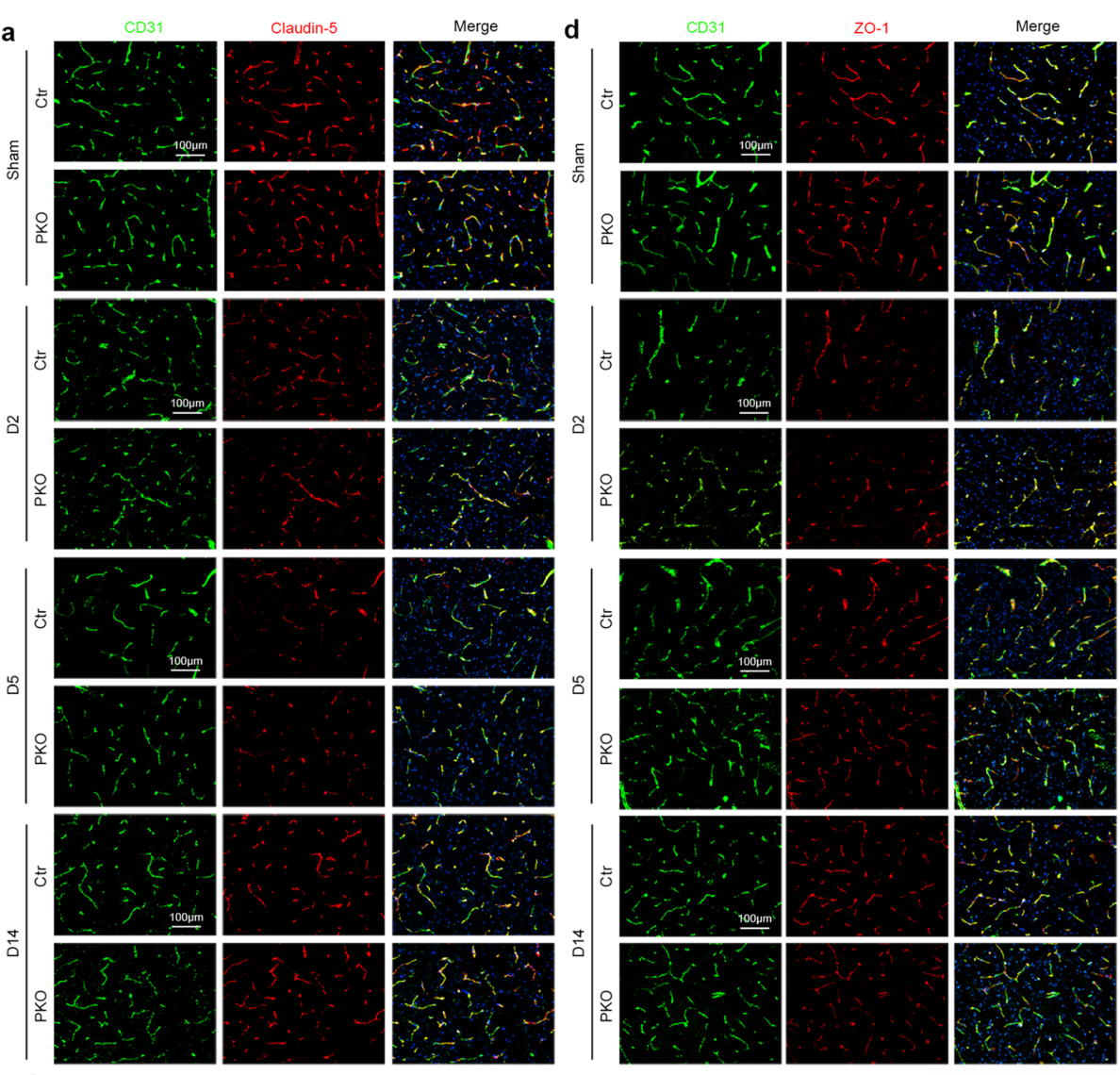

b
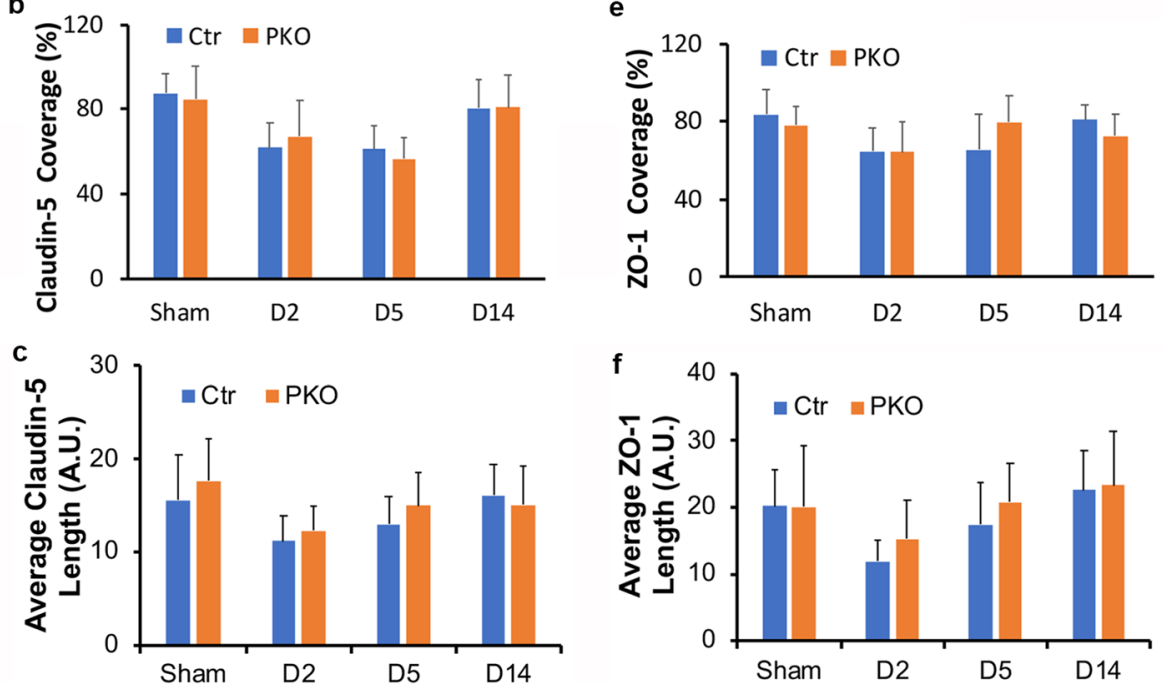

Fig. 3 Loss of mural cell-derived laminin does not affect paracellular transport after ICH. a Immunohistochemistry of CD31 (green)/claudin-5 (red) in control and PKO brains from sham group and D2, D5, and D14 after ICH. $\mathbf{b}$ Quantification of claudin-5 coverage in control and PKO brains. $n=$ 5. c Quantification of average claudin-5 length in control and PKO brains. $n=5$. $\mathbf{d}$ Immunohistochemistry of CD31 (green)/ZO-1 (red) in control and PKO brains from sham group and D2, D5, and D14 after ICH. e Quantification of ZO-1 coverage in control and PKO brains. $n=5$. $\mathbf{f}$ Quantification of average ZO-1 length in control and PKO brains. $n=5$. Data are shown as mean \pm SD

controls (Fig. 4a), indicating enhanced transcellular transport in PKO brains. These results suggest that mural cell-derived laminin negatively regulates transcellular transport in endothelial cells after ICH.
Mural cell-derived laminin inhibits transcytosis by downregulating caveolin-1

To explore the molecular mechanism underlying mural cell-derived laminin's effect on transcytosis in endothelial 


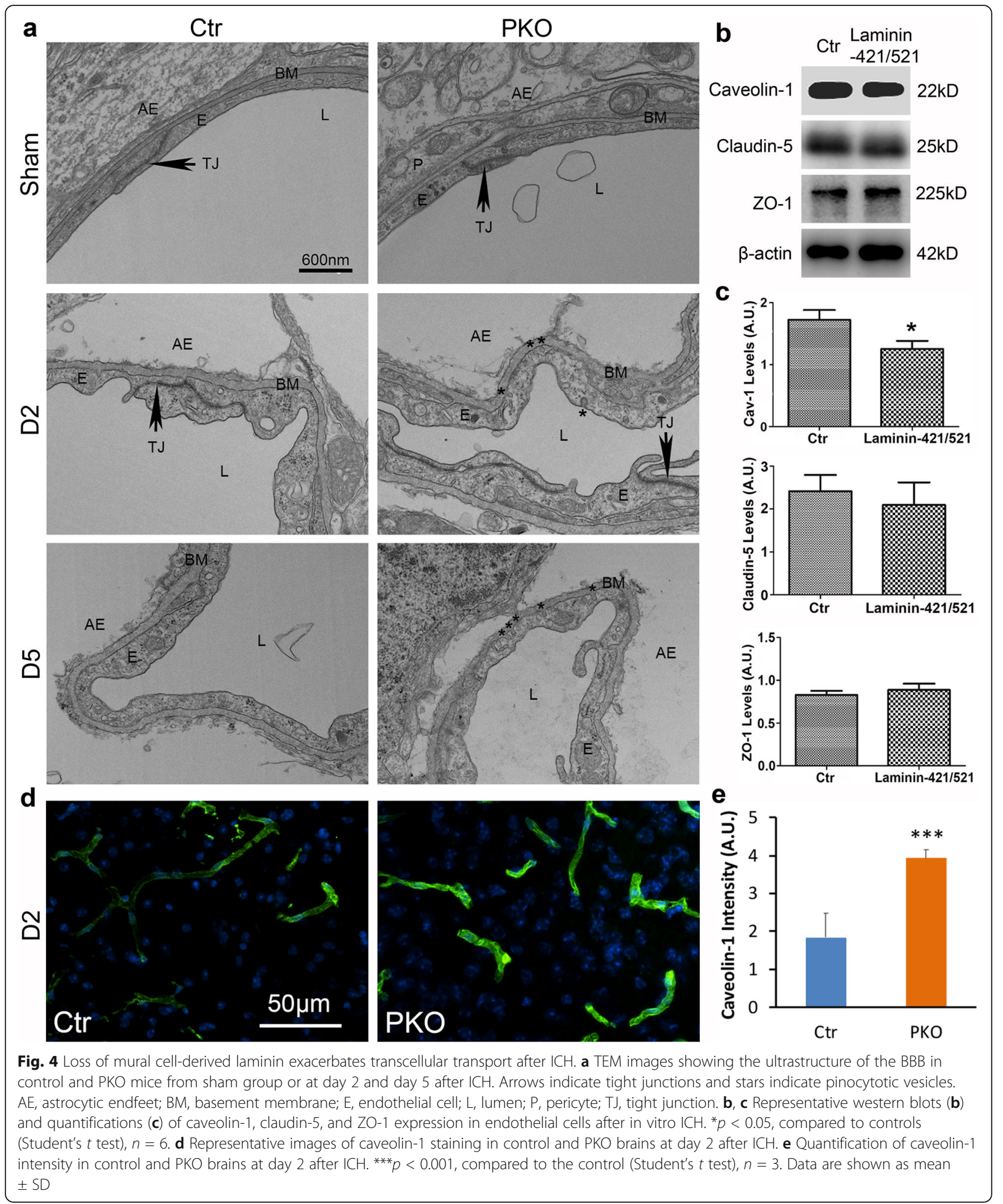

cells after $\mathrm{ICH}$, we moved to a simplified in vitro $\mathrm{ICH}$ model that involves hemoglobin and microglia-conditioned medium [42]. Previous studies have shown that caveolaemediated transcytosis plays an important role in BBB permeability regulation [51-53]. To determine if mural cell-derived laminin regulates transcytosis by targeting this pathway, we examined the expression of caveolin-1, a protein indispensable for caveolae-mediated transcytosis [54, 
55]. We found that exogenous mural cell-derived laminin (laminin-421/521) significantly reduced caveolin-1 expression without affecting the levels of claudin-5 and ZO-1 in bEnd. 3 cells in this in vitro ICH model (Fig. 4b, c), suggesting that mural cell-derived laminin inhibits transcytosis by downregulating caveolin-1 in endothelial cells after ICH.

To further investigate the role of mural cell-derived laminin in caveolin-1 expression in vivo, we examined caveolin-1 expression in control and PKO brains at day 2 after $\mathrm{ICH}$, a time point when enhanced BBB leakage was observed in PKO mice (Fig. 2c, d). Consistent with previous reports that caveolin-1 is predominantly expressed in endothelial cells in the brain [56-59], caveolin-1 displayed a blood vessel-like pattern in the brain (Fig. 4d). Compared to the controls, caveolin-1 fluorescent intensity was significantly increased in PKO brains at day 2 after ICH (Fig. 4d, e), suggesting that mural cell-derived laminin negatively regulates caveolin-1 expression in brain endothelial cells after ICH. Altogether, these findings suggest that mural cell-derived laminin inhibits transcytosis by downregulating caveolin-1 in brain endothelial cells after ICH.

\section{Loss of mural cell-derived laminin fails to affect pericyte coverage after ICH}

Accumulating evidence suggests that pericyte coverage actively contributes to BBB maintenance [60-62]. To determine if reduced pericyte coverage contributes to the elevated BBB permeability in PKO mice after ICH, we performed immunohistochemistry against vascular marker CD31 and pericyte marker PDGFR $\beta$. Consistent with our previous finding that pericyte coverage is unchanged in PKO mice at young age [28], sham mice showed comparable and high levels of pericyte coverage between genotypes $(85.66 \pm 4.19$ for control and $82.85 \pm$ 10.07 for PKO) (Fig. 5a). After ICH, control mice showed an initial reduction of pericyte coverage at day 2 $(64.22 \pm 11.89)$ and day 5 (64.06 \pm 15.36$)$, and a subsequent increase of pericyte coverage by day $14(90.10 \pm$ 18.77) (Fig. 5a, b). Pericyte coverage changes in PKO mutants $(54.49 \pm 9.26,59.04 \pm 12.06$, and $82.25 \pm 23.96$ at day 2 , day 5 , and day 14 after injury, respectively) mimicked those in control mice (Fig. 5a, b). Comparison between genotypes revealed no statistical significance at any time point (Fig. 5b). These results suggest that loss of mural cell-derived laminin does not affect pericyte coverage after $\mathrm{ICH}$.

\section{PKO mice show enhanced inflammatory cell extravasation} after ICH

Inflammatory cells infiltrate into brain parenchyma after $\mathrm{ICH}$. To determine if this process is affected by loss of mural cell-derived laminin, we examined inflammatory cell extravasation by immunohistochemistry. First, we examined neutrophil infiltration using Ly6G. Few Ly6G ${ }^{+}$cells were detected

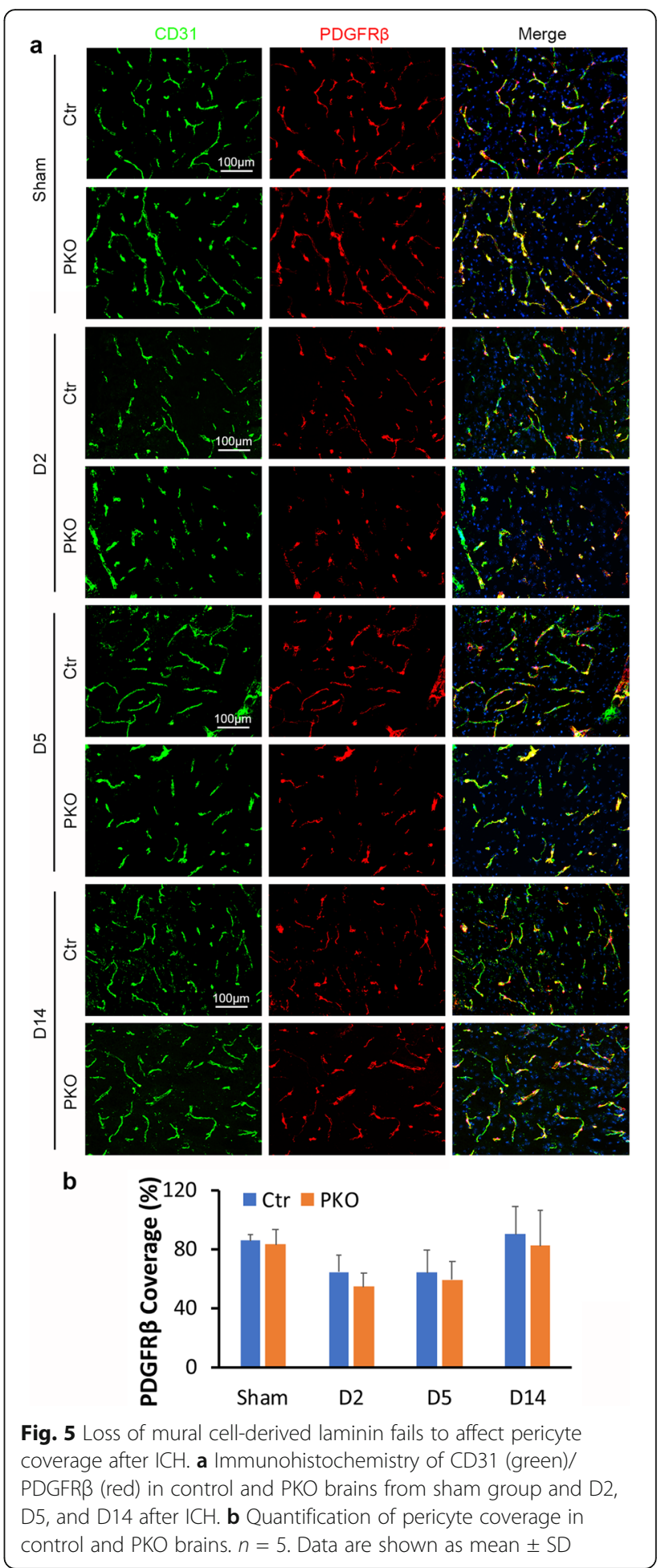

in sham animals (Fig. 6a). In control mice, the numbers of ${\text { Ly } 6 G^{+}}^{+}$neutrophils were high at day $2(54.88 \pm 12.01)$ and day 5 (57.01 \pm 9.64$)$ after injury, but low at day $14(28.70 \pm$ 13.79) after injury (Fig. 6a, b). Unlike control mice, PKO mice showed a continuous increase of $\mathrm{Ly}_{6 \mathrm{G}}{ }^{+}$neutrophils after ICH $(60.35 \pm 9.90,70.40 \pm 37.06$, and $83.96 \pm 22.31$ at 


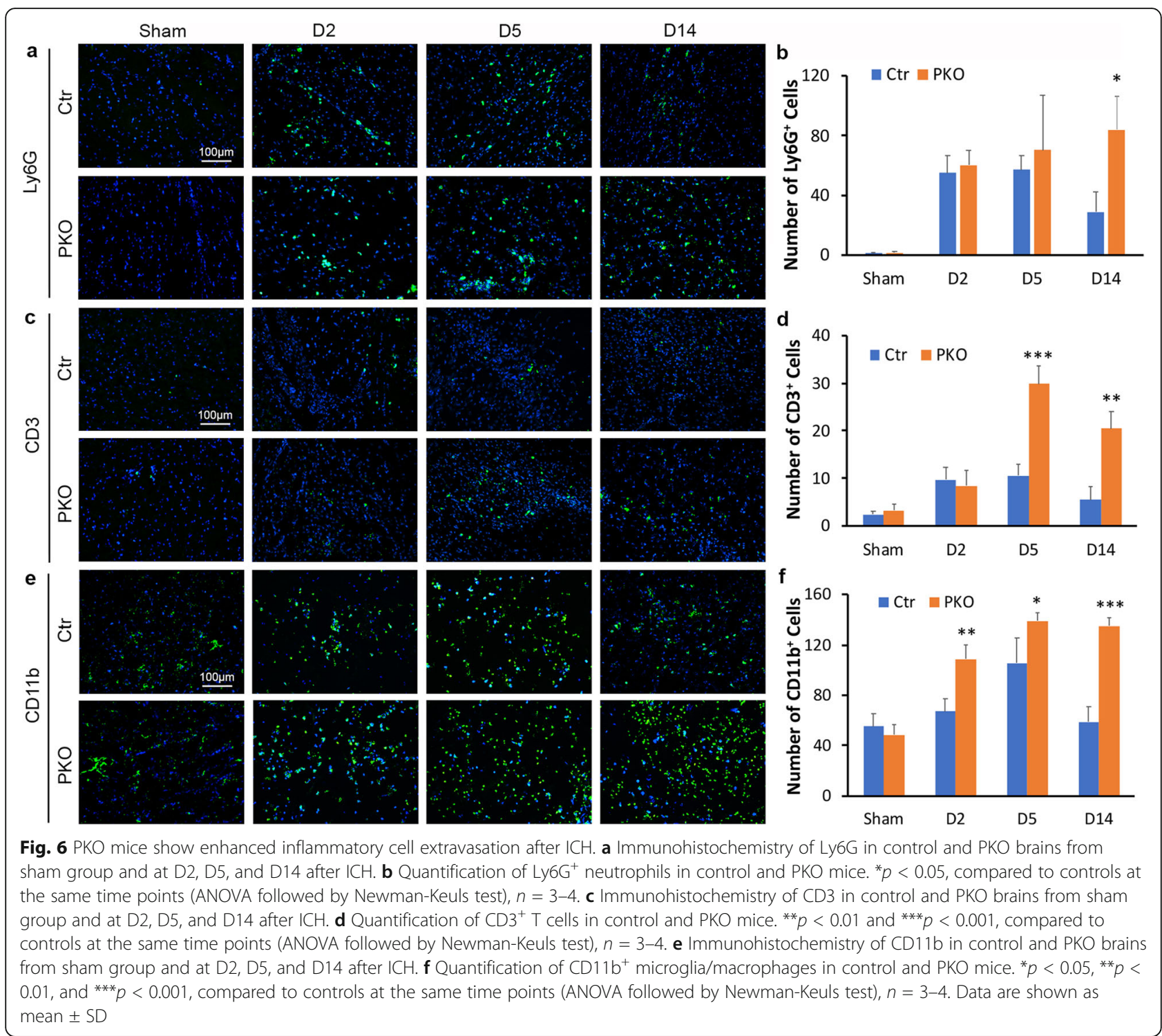

day 2, day 5 , and day 14 after injury, respectively) (Fig. 6a, b). Comparison between genotypes revealed statistical significance at day 14 after injury, indicating increased extravasation of neutrophils in PKO brains.

Next, we examined T cell extravasation using CD3. Similarly, $\mathrm{CD}^{+}$cells were barely detected in sham animals (Fig. 6c). In control mice, $\mathrm{T}$ cells were slightly increased at injury $(9.67 \pm$ 2.57, $10.58 \pm 2.34$, and $5.57 \pm 2.79$ at day 2 , day 5 , and day 14 after injury, respectively) (Fig. 6c, d). Compared to the controls, significantly more $\mathrm{CD}^{+}$cells were detected in PKO mice at day $5(29.83 \pm 3.89)$ and day $14(20.45 \pm 3.62)$ after injury (Fig. 6c, d), suggesting enhanced $\mathrm{T}$ cell infiltration.

Furthermore, we examined monocyte/macrophage extravasation using $\mathrm{CD} 11 \mathrm{~b}$. Consistent with previous reports that $\mathrm{CD} 11 \mathrm{~b}$ is able to label brain-resident microglia in addition to monocytes/macrophages [63, 64], $\mathrm{CD} 11 \mathrm{~b}^{+}$cells (microglia) were detected in sham animals (Fig. 6e). Quantification of $\mathrm{CD} 11 \mathrm{~b}^{+}$cells showed no statistical significance between genotypes in sham animals $(55.33 \pm 10.25$ in control and $48.29 \pm 8.04$ in PKO) (Fig. 6f), suggesting a dispensable role of mural cell-derived laminin in microglial number without $\mathrm{ICH}$. After $\mathrm{ICH}$, the number of $\mathrm{CD}_{11} \mathrm{~b}^{+}$cells peaked at day 5 $(105.47 \pm 20.29)$ after injury and decreased by day 14 $(58.68 \pm 12.03)$ after injury in control mice (Fig. 6e, f). Although $\mathrm{CD}_{11 \mathrm{~b}^{+}}$cells peaked at day $5(138.78 \pm 6.78)$ after injury in PKO mice, they remained high at day 14 $(134.86 \pm 6.90)$ after injury (Fig. 6e, f). Compared to controls, PKO mice demonstrated significantly more $\mathrm{CD}_{11} \mathrm{~b}^{+}$cells at all three time points examined (Fig. $6 \mathrm{f}$ ), suggesting increased monocyte/macrophage extravasation. Together, these findings strongly suggest that mural cell-derived laminin negatively regulates inflammatory cell infiltration after $\mathrm{ICH}$. 


\section{PKO mice show abnormal microglial activation at the recovery phase after $\mathrm{ICH}$}

$\mathrm{ICH}$ induces reactive astrogliosis and microglial activation [65-67]. To determine if loss of mural cell-derived laminin affects these processes, reactive astrogliosis and microglial activation were examined by GFAP and Iba1 staining, respectively. Weak GFAP signal was found in sham animals (Fig. 7a). Quantification revealed comparable GFAP intensity in sham control $(9.80 \pm 3.41)$ and sham PKO $(8.29 \pm 2.87)$ mice (Fig. 7b). After ICH, GFAP signal increased at day $2(16.76 \pm 3.19)$, peaked at day 5 $(25.97 \pm 8.70)$, and slightly decreased at day 14 (20.76 \pm 7.17) in control mice (Fig. 7a, b). A similar pattern was observed in PKO mice $(16.30 \pm 2.22,23.30 \pm 14.32$, and $16.95 \pm 6.62$, at day 2 , day 5 , and day 14 after injury, respectively) (Fig. 7a, b). Quantification showed that GFAP levels were comparable between genotypes at each time point, suggesting that loss of mural cell-derived laminin does not affect astrogliosis after ICH.

$\mathrm{Iba}^{+}$cells displayed ramified morphology (microglia) in sham animals (Fig. 7c). Quantification revealed comparable numbers of $\mathrm{Ibal}^{+}$cells in sham control $(30.20 \pm 3.56)$ and sham PKO (29.00 \pm 3.94$)$ mice (Fig. 7d), suggesting a dispensable role of mural cell-derived laminin in microglial number under homeostatic condition. After $\mathrm{ICH}, \mathrm{Ibal}^{+}$cells changed to an ameboid morphology in both control and PKO mice (Fig. 7c), indicating microglial activation. In control mice, the number of $\mathrm{Ibal}^{+}$microglia peaked at day 5 after injury $(71.85 \pm 15.73)$ and decreased at day 14 after injury $(31.59 \pm 9.01)$ (Fig. $7 d)$. Unlike in control mice, Iba1 ${ }^{+}$ microglia number remained high at day 14 after injury (68.04 \pm 8.93$)$ in PKO mice (Fig. 7d). Quantification revealed significantly increased $\mathrm{Ibal}^{+}$microglia in PKO brains at day 14 after injury but not at earlier time points (Fig. 7d). These results suggest that mural cell-derived laminin negatively regulate microglial number at the recovery phase after $\mathrm{ICH}$.

PKO mice show elevated brain water content before and after ICH

Red blood cell lysis, hemoglobin toxicity, BBB disruption, and inflammatory cell extravasation contribute to edema formation after $\mathrm{ICH}[68,69]$. To determine if lack of mural cell-derived laminin exacerbates brain edema, we measured brain water content in control and PKO mice at various time points after $\mathrm{ICH}$. Compared to controls, PKO mice showed significantly higher brain water content in the ipsilateral hemisphere at day 5 (79.07 \pm 0.40 in control and $80.71 \pm 0.86$ in PKO), but not at day 2 (79.78 \pm 0.90 in control and $79.87 \pm 0.33$ in PKO) or day 14 (78.28 \pm 0.34 in control and $78.72 \pm 0.62$ in PKO) after injury (Table 1), suggesting an important role of mural cellderived laminin in brain water homeostasis after $\mathrm{ICH}$.

In addition, we also compared brain water content between contralateral and ipsilateral hemispheres within each genotype. In control mice, the ipsilateral hemisphere showed significantly higher brain water content

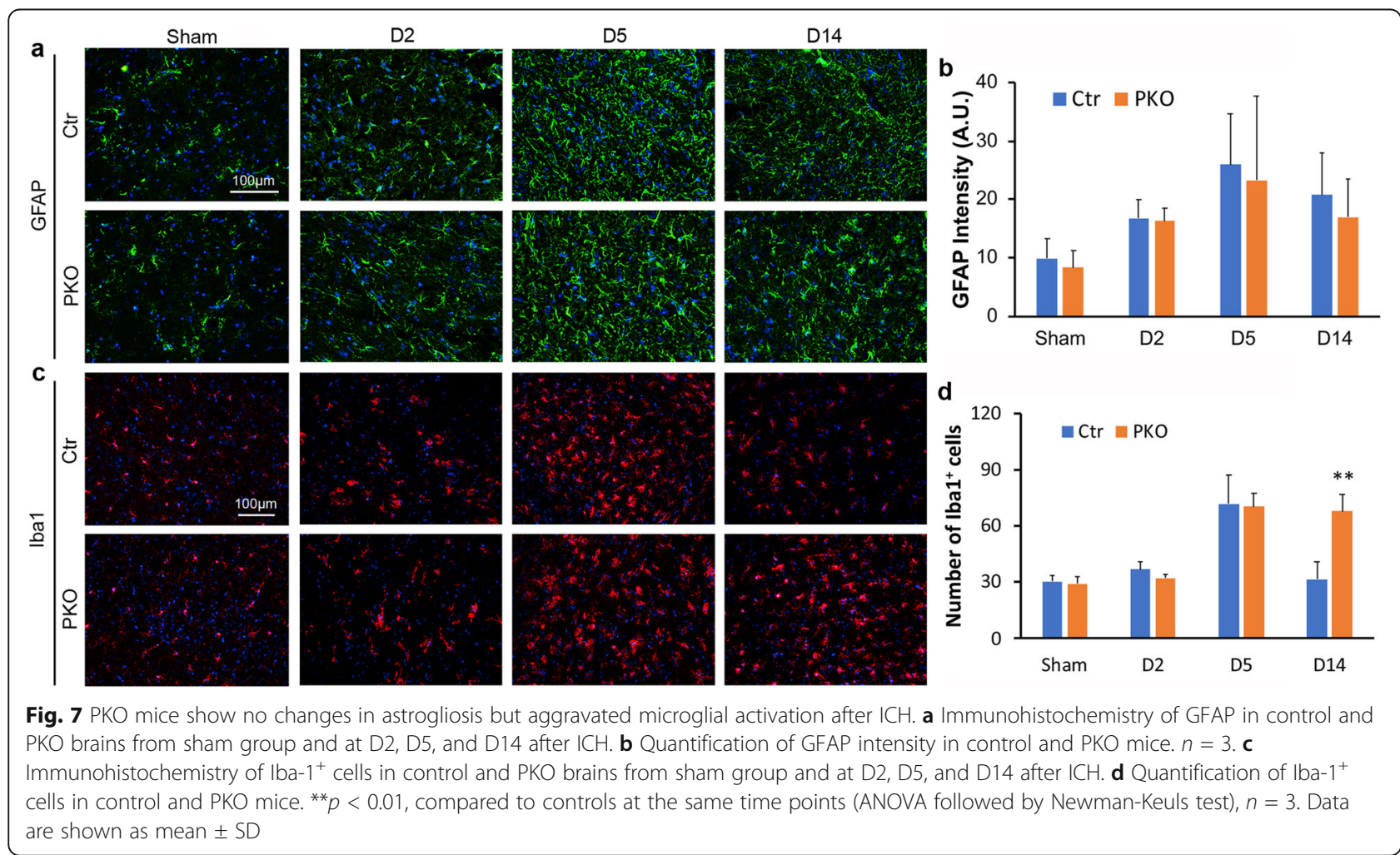


Table 1 Brain water content in control and PKO mice

\begin{tabular}{lclll}
\hline Genotype & Group & \multicolumn{3}{l}{ Brain water content (\%) } \\
\cline { 3 - 5 } & & Contralateral & Ipsilateral & Cerebellum \\
\hline Control & Sham & $78.56 \pm 0.24$ & $78.50 \pm 0.22$ & $77.33 \pm 0.37$ \\
& D2 & $78.64 \pm 0.58$ & $79.78 \pm 0.90^{\# \#}$ & $76.95 \pm 0.51$ \\
& D5 & $78.59 \pm 0.30$ & $79.07 \pm 0.40$ & $76.98 \pm 0.52$ \\
PKO & D14 & $77.95 \pm 0.39$ & $78.28 \pm 0.34$ & $76.93 \pm 0.52$ \\
& Sham & $79.80 \pm 0.18^{* *}$ & $79.72 \pm 0.43^{* *}$ & $79.01 \pm 0.60^{* *}$ \\
& D2 & $79.50 \pm 0.32$ & $79.87 \pm 0.33$ & $78.67 \pm 0.40$ \\
& D5 & $79.97 \pm 0.53$ & $80.71 \pm 0.86^{* *}$ & $78.49 \pm 0.25$ \\
& D14 & $78.73 \pm 0.49$ & $78.72 \pm 0.62$ & $77.67 \pm 0.89$ \\
\hline
\end{tabular}

$\# \#<0.01$, compared to contralateral hemisphere within the same genotype; ${ }^{* *} p<0.01$, compared to wildtype controls. Student's $t$ test. $n=4-10$

at day 2 after $\mathrm{ICH}(79.78 \pm 0.90)$, which slowly went down overtime $(79.07 \pm 0.40$ and $78.28 \pm 0.34$ at day 5 and day 14 after injury, respectively) (Table 1), indicating successful induction of ICH. In PKO mice, however, the contralateral and ipsilateral hemispheres displayed comparable brain water content (Table 1). This is mainly due to the high baseline brain water content in the contralateral hemisphere in PKO mice (78.64 \pm 0.58, $78.59 \pm 0.30$, and $77.95 \pm 0.39$ in control vs. $79.50 \pm$ $0.32,79.97 \pm 0.53$, and $78.73 \pm 0.49$ in $\mathrm{PKO}$ at day 2 , day 5 , and day 14 after $\mathrm{ICH}$, respectively) (Table 1 ). Similar changes were observed in the cerebellum (76.95 \pm 0.51 , $76.98 \pm 0.52$, and $76.93 \pm 0.52$ in control vs. $78.67 \pm$ $0.40,78.49 \pm 0.25$, and $77.67 \pm 0.89$ in $\mathrm{PKO}$ at day 2 , day 5 , and day 14 after $\mathrm{ICH}$, respectively) (Table 1 ).

To determine if the enhanced baseline brain water content in $\mathrm{PKO}$ mice is intrinsic to the mutants or induced by $\mathrm{ICH}$, we further examined brain water content in sham animals. Compared to the controls, PKO mice demonstrated significantly higher levels of brain water content in contralateral hemisphere (78.56 \pm 0.24 in control vs. $79.80 \pm 0.18$ in $\mathrm{PKO}$ ), ipsilateral hemisphere (78.50 \pm 0.22 in control vs. $79.72 \pm 0.43$ in PKO), and cerebellum $(77.33 \pm 0.37$ in control vs. $79.01 \pm 0.60$ in PKO) (Table 1). These results suggest an indispensable role of mural cell-derived laminin in brain water homeostasis independent of ICH.

\section{AQP4 level is unaffected in PKO mice}

As an important water channel expressed exclusively at astrocytic endfeet, AQP4 actively regulates water homeostasis in the brain $[70,71]$. To determine if the enhanced brain water content in PKO mice is caused by abnormal AQP4 expression, we performed immunohistochemistry against AQP4 and vascular marker CD31 (Fig. 8a). Consistent with our previous report [28], comparable AQP4 coverage (82.19 \pm 11.31 in control and $63.23 \pm 14.33$ in PKO) were found in sham animals (Fig. 8a, b). Similarly, no difference in AQP4 coverage was observed between

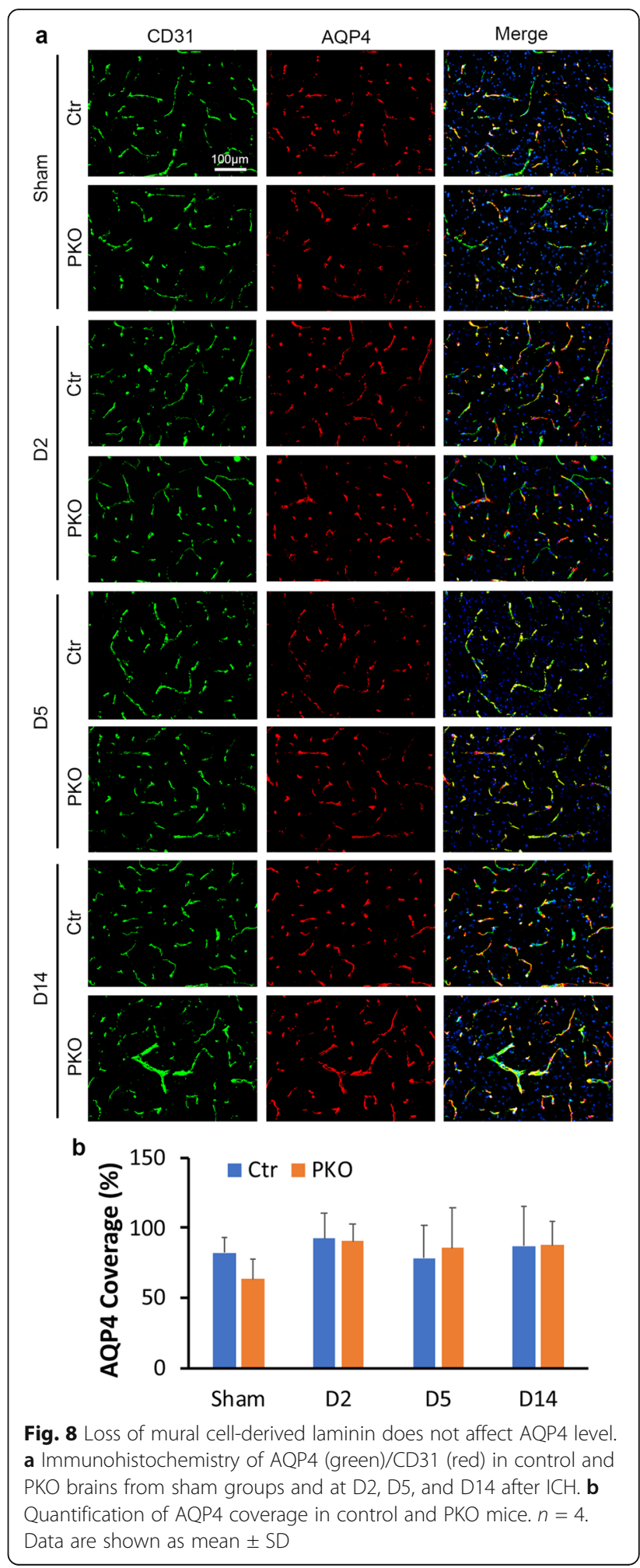

genotypes at any time point after $\mathrm{ICH}(92.11 \pm 18.39$, $78.34 \pm 23.60$, and $87.03 \pm 28.03$ in control vs. $90.19 \pm$ 13.02, 85.49 \pm 28.97, and 87.28 \pm 17.25 in PKO at day 2, day 5 , and day 14 after $\mathrm{ICH}$, respectively) (Fig. $8 \mathrm{a}, \mathrm{b}$ ). 
These results suggest that the abnormally high brain water content in $\mathrm{PKO}$ mice is AQP4-independent.

\section{Discussion}

In this study, we examined brain injury in PKO mice using collagenase-induced ICH model. The PKO mice displayed worse outcomes after $\mathrm{ICH}$, including enlarged hematoma volume, aggravated neurological dysfunction, increased neuronal degeneration, exacerbated BBB disruption, enhanced inflammatory cell infiltration, and elevated microglial activation, suggesting that mural cell-derived laminin plays a beneficial role after $\mathrm{ICH}$. We further demonstrated that mural cell-derived laminin maintains BBB integrity by downregulating caveolin-1 and thus transcytosis in endothelial cells after ICH.

The functional significance of laminin in $\mathrm{ICH}$ is largely unknown. Previous correlation studies revealed reduced laminin levels in ICH brains and in hemorrhagic areas of ischemic brains [72, 73], although the specific laminin isoforms reduced were not reported, suggesting a possibly neuroprotective role of laminin in $\mathrm{ICH}$. Consistent with this speculation, we demonstrated that mice lacking astrocytic laminin developed severe BBB disruption and agedependent spontaneous ICH [20, 25], suggesting a causative role of astrocytic laminin in $\mathrm{ICH}$ pathogenesis. In addition, in a recent study, we reported that endothelium-specific laminin- $\alpha 5$ conditional knockout mice were grossly normal under homeostatic condition but showed exacerbated brain injury in collagenase-induced ICH [26], indicating a beneficial role of endothelial laminin- $\alpha 5$. Consistent with these findings, here we showed that mural cell-derived laminin also contributes to $\mathrm{ICH}$ pathogenesis. Given that ablation of astrocytic laminin leads to spontaneous ICH [25], while loss of endothelial laminin- $\alpha 5$ [26] or mural cell-derived laminin only aggravated brain injury in collagenase-induced ICH model, we conclude that astrocytic laminin exerts a more important role in $\mathrm{ICH}$ pathogenesis, compared to endothelium- or mural cell-derived laminins.

One important pathological change induced by $\mathrm{ICH}$ is microglial activation [67, 74, 75]. We observed increased microglia in PKO mice at the recovery phase after ICH, suggesting that mural cell-derived laminin negatively regulates microglial number. Similarly, mice with laminin- $\alpha 5$ deficiency in endothelial cells displayed higher microglial density after ICH [26]. In addition, loss of laminin $\gamma 3$ from the retinal vascular plexus significantly increases microglial density and activation in vitro and in vivo [76]. These results suggest that laminin may negatively regulate microglial density and activation.

Unlike control mice, the PKO mice failed to show enhanced brain water content in the ipsilateral hemisphere after ICH. This is mainly due to the abnormally high brain water content in the contralateral hemisphere in these mutants. We further demonstrated elevated brain water content in $\mathrm{PKO}$ mice under homeostatic condition, indicating an important role of mural cell-derived laminin in brain water homeostasis. Accumulating evidence suggests that the permeability of cell membrane to water is controlled by a group of water channel proteins called aquaporins, especially AQP4. For example, AQP4 expression in astrocytic endfeet has been shown to be responsible for the development of the cerebral edema during hemorrhagic stroke [77]. In addition, decreased AQP4 expression leads to increased brain water content in cerebral malaria [78]. Consistent with these results, both AQP4 null mice and glial cell-specific AQP4 conditional knockout mice exhibit slightly higher baseline brain water content under homeostatic condition $[79,80]$. Furthermore, AQP4 null mice also displayed elevated brain water content in the ipsilateral hemisphere after ICH $[81,82]$. In contrast to these studies, we found unchanged AQP4 expression in PKO brains, suggesting that the enhanced baseline brain water content in PKO mice is AQP4-independent. The question then becomes how exactly abrogation of mural cellderived laminin leads to increased brain water content? One possibility is that mural cell-derived laminin may regulate brain water homeostasis via other AQPs, such as $\mathrm{AQP1}$. It has been reported that AQP1 expression is also involved in cerebral edema formation in hemorrhagic stroke [77]. Another possibility is that mural cell-derived laminin may regulate osmolality between brain parenchyma and the extracellular matrix, the imbalance of which results in abnormal brain water content. These possibilities will be explored in future studies.

The PKO mice were generated by crossing the laminin- $\gamma 1^{\text {flox/flox }}$ mice and the PDGFR $\beta$-Cre line. Since PDGFR $\beta$ labels both pericytes and vascular smooth muscle cells (vSMCs) in the brain [83, 84], we are unable to distinguish whether the changes in PKO mice are due to loss of pericyte- or vSMC-derived laminin. Given that (1) vSMC-specific laminin- $\gamma 1$ conditional knockout (termed SKO) mice have a normal lifespan and are grossly normal [24] and (2) PKO but not SKO mice show age-dependent BBB breakdown [28], we speculate that the PKO phenotype reported in this study is more likely to be caused by loss of pericyte- rather than vSMC-derived laminin. However, we cannot exclude the possibility that vSMC-derived laminin also contributes to $\mathrm{ICH}$ pathogenesis.

Mural cells predominantly synthesize $\alpha 4 / \alpha 5$ - and $\gamma 1$ containing laminins $[24,28]$. We have shown that mice lacking laminin- $\alpha 5$ in mural cells ( $\alpha 5-\mathrm{PKO})$ are grossly normal under homeostatic condition [85], while those lacking laminin- $\gamma 1$ in mural cells develop age-dependent BBB breakdown [28]. The relatively milder phenotype of $\alpha 5-\mathrm{PKO}$ mice is consistent with the fact that ablation of 
laminin- $\gamma 1$ results in loss of both laminin- $\alpha 4$ and $-\alpha 5$ in mural cells [28]. These findings suggest an important role of mural cell-derived laminin- $\alpha 4$ in BBB maintenance under homeostatic condition. In addition, $\alpha 5-\mathrm{PKO}$ mutants displayed improved outcomes after ischemic stroke [85], suggesting a detrimental role of mural cellderived laminin- $\alpha 5$ in ischemic stroke; whereas PKO mice showed worse outcomes after $\mathrm{ICH}$, suggesting a beneficial role of mural cell-derived laminin- $\gamma 1$ in hemorrhagic stroke. This discrepancy could be explained by different stroke models. Ischemic stroke and hemorrhagic stroke have different pathology in the brain [86-88]. It is possible that the different outcomes are due to distinct brain pathology. An alternative explanation is that mural cell-derived laminin- $\alpha 4$ plays a neuroprotective role, while mural cell-derived laminin- $\alpha 5$ plays a detrimental role, with the former being the dominant isoform in mural cells. We are actively testing these possibilities in our laboratory.

\section{Conclusions}

Our results strongly suggest that (1) loss of mural cellderived laminin exacerbates BBB damage and $\mathrm{ICH}$ outcomes, (2) mural cell-derived laminin negatively regulates transcytosis by downregulating caveolin-1 in endothelial cells after $\mathrm{ICH}$, and (3) mural cell-derived laminin regulates brain water content in an AQP4independent manner.

\section{Abbreviations \\ AQP4: Aquaporin-4; BBB: Blood-brain barrier; BM: Basement membrane; BMECs: Brain microvascular endothelial cells; FJC: Fluoro-Jade C; $\mathrm{ICH}$ : Intracerebral hemorrhage; PFA: Paraformaldehyde; PKO: Laminin- $\gamma 1^{\text {flox/flox }}$ :PDGFRß-Cre $;$ SKO: Laminin- $\gamma 1^{\text {flox/flox }}$ :transgelin-Cre ${ }^{+}$; TEM: Transmission electron microscopy; TJP: Tight junction protein; vSMC: Vascular smooth muscle cells}

\section{Acknowledgements}

We thank Dr. Volkhard Lindner (Maine Medical Center Research Institute) for the PDGFRß-Cre mice. We also thank the Yao lab members for scientific discussion and suggestions.

\section{Authors' contributions}

YY conceived and designed the experiments, performed data analyses, and wrote the manuscript. JG performed the experiments, collected and analyzed the data, and wrote the manuscript. LX performed the experiments, collected and analyzed the data, and wrote the manuscript. AN performed the experiments and collected and analyzed the data. BN contributed to data analyses. All authors have read and approved the final submission.

\section{Funding}

This work was partially supported by the AHA Scientist Development Grant (16SDG29320001) to YY and NIH R01 Grant (R01HL146574) to YY.

\section{Availability of data and materials}

All data generated or analyzed during this study are included in this published article.

\section{Ethics approval and consent to participate}

All applicable international, national, and/or institutional guidelines for the care and use of animals were followed. This study was approved by the Institutional Animal Care and Use Committee at the University of Georgia.
This study does not contain any studies with human participants performed by any of the authors.

\section{Consent for publication}

Not applicable.

\section{Competing interests}

The authors declare that they have no competing interests.

Received: 20 January 2020 Accepted: 25 March 2020

Published online: 06 April 2020

\section{References}

1. Veltkamp R, Purrucker J. Management of spontaneous intracerebral hemorrhage. Curr Neurol Neurosci Rep. 2017;17:80.

2. Sacco S, Marini C, Toni D, Olivieri L, Carolei A. Incidence and 10-year survival of intracerebral hemorrhage in a population-based registry. Stroke. 2009;40:394-9.

3. Cordonnier C, Demchuk A, Ziai W, Anderson CS. Intracerebral haemorrhage: current approaches to acute management. Lancet. 2018;392:1257-68.

4. Lo EH, Rosenberg GA. The neurovascular unit in health and disease: introduction. Stroke. 2009;40:S2-3.

5. McConnell HL, Kersch CN, Woltjer RL, Neuwelt EA. The translational significance of the neurovascular unit. J Biol Chem. 2017;292:762-70.

6. Yao Y. Basement membrane and stroke. J Cereb Blood Flow Metab. 2019;39:3-19.

7. Muoio V, Persson PB, Sendeski MM. The neurovascular unit - concept review. Acta Physiol (Oxf). 2014:210:790-8.

8. Hawkins BT, Davis TP. The blood-brain barrier/neurovascular unit in health and disease. Pharmacol Rev. 2005;57:173-85.

9. Nirwane A, Yao Y. Laminins and their receptors in the CNS. Biol Rev Camb Philos Soc. 2019;94:283-306.

10. Takada Y, Ye X, Simon S. The integrins. Genome Biol. 2007;8:215.

11. Edwards DN, Bix GJ. Roles of blood-brain barrier integrins and extracellular matrix in stroke. Am J Physiol Cell Physiol. 2019;316:C252-63.

12. Wu X, Reddy DS. Integrins as receptor targets for neurological disorders. Pharmacol Ther. 2012;134:68-81.

13. Roberts J, de Hoog L, Bix GJ. Mice deficient in endothelial alpha5 integrin are profoundly resistant to experimental ischemic stroke. J Cereb Blood Flow Metab. 2017;37:85-96.

14. Kang M, Yao Y. Basement membrane changes in ischemic stroke. Stroke. 2020; In Press.

15. Yao Y. Laminin: loss-of-function studies. Cell Mol Life Sci. 2017;74:1095-115.

16. Aumailley M. The laminin family. Cell Adh Migr. 2013;7:48-55.

17. Durbeej M. Laminins. Cell Tissue Res. 2010;339:259-68.

18. Hannocks M-J, Huppert J, Zhang X, Korpos E, Sorokin L. The contribution of the extracellular matrix to the BBB in steady state and inflammatory conditions. In The Blood Brain Barrier and Inflammation. Springer. 2017:49-60.

19. Menezes MJ, McClenahan FK, Leiton CV, Aranmolate A, Shan X, Colognato $\mathrm{H}$. The extracellular matrix protein laminin alpha2 regulates the maturation and function of the blood-brain barrier. J Neurosci. 2014;34:15260-80.

20. Yao Y, Chen ZL, Norris EH, Strickland S. Astrocytic laminin regulates pericyte differentiation and maintains blood brain barrier integrity. Nat Commun. 2014;5:3413.

21. Sixt M, Engelhardt B, Pausch F, Hallmann R, Wendler O, Sorokin LM. Endothelial cell laminin isoforms, laminins 8 and 10, play decisive roles in T cell recruitment across the blood-brain barrier in experimental autoimmune encephalomyelitis. J Cell Biol. 2001;153:933-46.

22. Yousif LF, Di Russo J, Sorokin L. Laminin isoforms in endothelial and perivascular basement membranes. Cell Adh Migr. 2013;7:101-10.

23. Di Russo J, Luik AL, Yousif L, Budny S, Oberleithner H, Hofschröer V, Klingauf J, van Bavel E, Bakker EN, Hellstrand P. Endothelial basement membrane laminin 511 is essential for shear stress response. EMBO J. 2016:e201694756.

24. Gautam J, Zhang X, Yao Y. The role of pericytic laminin in blood brain barrier integrity maintenance. Sci Rep. 2016;6:36450.

25. Chen ZL, Yao Y, Norris EH, Kruyer A, Jno-Charles O, Akhmerov A, Strickland S. Ablation of astrocytic laminin impairs vascular smooth muscle cell function and leads to hemorrhagic stroke. J Cell Biol. 2013;202:381-95.

26. Gautam J, Miner JH, Yao Y. Loss of endothelial laminin alpha5 exacerbates hemorrhagic brain injury. Transl Stroke Res. 2019;10:705-18.

27. Song J, Zhang X, Buscher K, Wang Y, Wang H, Di Russo J, Li L, Lütke-Enking S, Zarbock A, Stadtmann A. Endothelial basement membrane laminin 511 contributes to endothelial junctional tightness and thereby inhibits leukocyte transmigration. Cell Reports. 2017;18:1256-69. 
28. Gautam J, Cao Y, Yao Y. Pericytic laminin maintains blood-brain barrier integrity in an age-dependent manner. Transl Stroke Res. 2020; In Press.

29. Yao Y, Norris EH, Mason CE, Strickland S. Laminin regulates PDGFRbeta(+) cell stemness and muscle development. Nat Commun. 2016;7:11415

30. Yao Y, Tsirka SE. The CCL2-CCR2 system affects the progression and clearance of intracerebral hemorrhage. Glia. 2012;60:908-18.

31. Wang J, Rogove AD, Tsirka AE, Tsirka SE. Protective role of tuftsin fragment 1-3 in an animal model of intracerebral hemorrhage. Ann Neurol. 2003;54:655-64.

32. Wang J, Tsirka SE. Tuftsin fragment 1-3 is beneficial when delivered after the induction of intracerebral hemorrhage. Stroke. 2005;36:613-8.

33. Klahr AC, Dickson CT, Colbourne F. Seizure activity occurs in the collagenase but not the blood infusion model of striatal hemorrhagic stroke in rats. Transl Stroke Res. 2015:6:29-38.

34. Wu G, Xi G, Hua Y, Sagher O. T2* magnetic resonance imaging sequences reflect brain tissue iron deposition following intracerebral hemorrhage. Transl Stroke Res. 2010;1:31-4.

35. Wan $S$, Cheng Y, Jin H, Guo D, Hua Y, Keep RF, Xi G. Microglia activation and polarization after intracerebral hemorrhage in mice: the role of protease-activated receptor-1. Transl Stroke Res. 2016;7:478-87.

36. Clark W, Gunion-Rinker L, Lessov N, Hazel K. Citicoline treatment for experimental intracerebral hemorrhage in mice. Stroke. 1998;29:2136-40.

37. Schmued LC, Hopkins KJ. Fluoro-Jade B: a high affinity fluorescent marker for the localization of neuronal degeneration. Brain Res. 2000; 874:123-30.

38. Bell RD, Winkler EA, Sagare AP, Singh I, LaRue B, Deane R, Zlokovic BV. Pericytes control key neurovascular functions and neuronal phenotype in the adult brain and during brain aging. Neuron. 2010;68:409-27.

39. Keep RF, Hua Y, Xi G. Brain water content. A misunderstood measurement? Transl Stroke Res. 2012;3:263-5.

40. Manaenko A, Chen H, Kammer J, Zhang JH, Tang J. Comparison Evans blue injection routes: intravenous versus intraperitoneal, for measurement of blood-brain barrier in a mice hemorrhage model. J Neurosci Methods. 2011; 195:206-10.

41. Lu X, Chen-Roetling J, Regan RF. Systemic hemin therapy attenuates bloodbrain barrier disruption after intracerebral hemorrhage. Neurobiol Dis. 2014; 70:245-51.

42. Shen H, Liu C, Zhang D, Yao X, Zhang K, Li H, Chen G. Role for RIP1 in mediating necroptosis in experimental intracerebral hemorrhage model both in vivo and in vitro. Cell Death Dis. 2017;8:e2641.

43. Broderick JP, Brott TG, Duldner JE, Tomsick T, Huster G. Volume of intracerebral hemorrhage. A powerful and easy-to-use predictor of 30-day mortality. Stroke. 1993;24:987-93.

44. Christensen MC, Morris S, Vallejo-Torres L, Vincent C, Mayer SA. Neurological impairment among survivors of intracerebral hemorrhage: the FAST trial. Neurocrit Care. 2012:16:224-31.

45. Hemphill JC 3rd, Farrant M, Neill TA Jr. Prospective validation of the $\mathrm{ICH}$ Score for 12-month functional outcome. Neurology. 2009;73:1088-94.

46. Keep RF, Xiang J, Ennis SR, Andjelkovic A, Hua Y, Xi G, Hoff J. Blood-brain barrier function in intracerebral hemorrhage. Acta Neurochir Suppl. 2008;105:73-7.

47. Keep RF, Zhou N, Xiang J, Andjelkovic AV, Hua Y, Xi G. Vascular disruption and blood-brain barrier dysfunction in intracerebral hemorrhage. Fluids Barriers CNS. 2014;11:18.

48. Bauer HC, Krizbai IA, Bauer H, Traweger A. "You Shall Not Pass"-tight junctions of the blood brain barrier. Front Neurosci. 2014;8:392.

49. Luissint AC, Artus C, Glacial F, Ganeshamoorthy K, Couraud PO. Tight junctions at the blood brain barrier: physiological architecture and diseaseassociated dysregulation. Fluids Barriers CNS. 2012;9:23.

50. Greene C, Campbell M. Tight junction modulation of the blood brain barrier: CNS delivery of small molecules. Tissue Barriers. 2016;4:e1138017.

51. Andreone BJ, Lacoste B, Gu C. Neuronal and vascular interactions. Annu Rev Neurosci. 2015;38:25-46.

52. Andreone BJ, Chow BW, Tata A, Lacoste B, Ben-Zvi A, Bullock K, Deik AA, Ginty DD, Clish CB, Gu C. Blood-brain barrier permeability is regulated by lipid transport-dependent suppression of caveolae-mediated transcytosis. Neuron. 2017;94:581-94 e585.

53. Chow BW, Gu C. The molecular constituents of the blood-brain barrier. Trends Neurosci. 2015;38:598-608.

54. Cheng JPX, Nichols BJ. Caveolae: one function or many? Trends Cell Biol. 2016;26:177-89
55. Pelkmans L, Burli T, Zerial M, Helenius A. Caveolin-stabilized membrane domains as multifunctional transport and sorting devices in endocytic membrane traffic. Cell. 2004;118:767-80.

56. Virgintino D, Robertson D, Errede M, Benagiano V, Tauer U, Roncali L, Bertossi M. Expression of caveolin-1 in human brain microvessels. Neuroscience. 2002;115:145-52.

57. Jasmin JF, Malhotra S, Singh Dhallu M, Mercier I, Rosenbaum DM, Lisanti MP. Caveolin-1 deficiency increases cerebral ischemic injury. Circ Res. 2007;100:721-9.

58. Badaut J, Ajao DO, Sorensen DW, Fukuda AM, Pellerin L. Caveolin expression changes in the neurovascular unit after juvenile traumatic brain injury: signs of blood-brain barrier healing? Neuroscience. 2015;285:215-26.

59. MacDonald JL, Fame RM, Gillis-Buck EM, Macklis JD. Caveolin1 identifies a specific subpopulation of cerebral cortex callosal projection neurons (CPN) including dual projecting cortical callosal/frontal projection neurons (CPN/FPN). eNeuro. 2018:5:e0234-172017.

60. Wang Y, Pan L, Moens CB, Appel B. Notch3 establishes brain vascular integrity by regulating pericyte number. Development. 2014;141:307-17.

61. Hu E, Hu W, Yang A, Zhou H, Zhou J, Luo J, Wang Y, Tang T, Cui H. Thrombin promotes pericyte coverage by Tie2 activation in a rat model of intracerebral hemorrhage. Brain Res. 1708;2019:58-68.

62. Gautam J, Yao Y. Roles of pericytes in stroke pathogenesis. Cell Transplant. 2018:27:1798-808.

63. Greenhalgh AD, Zarruk JG, Healy LM, Baskar Jesudasan SJ, Jhelum P, Salmon CK, Formanek A, Russo MV, Antel JP, McGavern DB, et al. Peripherally derived macrophages modulate microglial function to reduce inflammation after CNS injury. PLoS Biol. 2018;16:e2005264.

64. Korzhevskii DE, Kirik OV. Brain microglia and microglial markers. Neurosci Behav Physiol. 2016;46:284-90.

65. Egashira Y, Hua Y, Keep RF, Xi G. Intercellular cross-talk in intracerebral hemorrhage. Brain Res. 1623;2015:97-109.

66. Chiu CD, Yao NW, Guo JH, Shen CC, Lee HT, Chiu YP, Ji HR, Chen X, Chen CC, Chang C. Inhibition of astrocytic activity alleviates sequela in acute stages of intracerebral hemorrhage. Oncotarget. 2017;8:94850-61.

67. Lan X, Han X, Li Q, Yang QW, Wang J. Modulators of microglial activation and polarization after intracerebral haemorrhage. Nat Rev Neurol. 2017;13:420-33.

68. Zheng H, Chen C, Zhang J, Hu Z. Mechanism and therapy of brain edema after intracerebral hemorrhage. Cerebrovasc Dis. 2016;42:155-69.

69. Xi G, Hua Y, Bhasin RR, Ennis SR, Keep RF, Hoff JT. Mechanisms of edema formation after intracerebral hemorrhage: effects of extravasated red blood cells on blood flow and blood-brain barrier integrity. Stroke. 2001;32:2932-8.

70. Nagelhus EA, Ottersen OP. Physiological roles of aquaporin-4 in brain. Physiol Rev. 2013;93:1543-62.

71. lacovetta C, Rudloff E, Kirby R. The role of aquaporin 4 in the brain. Vet Clin Pathol. 2012:41:32-44

72. Hamann GF, Okada Y, del Zoppo GJ. Hemorrhagic transformation and microvascular integrity during focal cerebral ischemia/reperfusion. J Cereb Blood Flow Metab. 1996;16:1373-8.

73. Scholler K, Trinkl A, Klopotowski M, Thal SC, Plesnila N, Trabold R, Hamann GF, Schmid-Elsaesser R, Zausinger S. Characterization of microvascular basal lamina damage and blood-brain barrier dysfunction following subarachnoid hemorrhage in rats. Brain Res. 2007;1142:237-46.

74. Gao Z, Wang J, Thiex R, Rogove AD, Heppner FL, Tsirka SE. Microglial activation and intracerebral hemorrhage. Acta Neurochir Suppl. 2008;105:51-3.

75. Wu J, Yang S, Xi G, Song S, Fu G, Keep RF, Hua Y. Microglial activation and brain injury after intracerebral hemorrhage. Acta Neurochir Suppl. 2008;105: 59-65.

76. Biswas S, Bachay G, Chu J, Hunter DD, Brunken WJ. Laminin-dependent interaction between astrocytes and microglia: a role in retinal angiogenesis Am J Pathol. 2017;187:2112-27.

77. Agre P, Kozono D. Aquaporin water channels: molecular mechanisms for human diseases. FEBS Lett. 2003;555:72-8.

78. Promeneur D, Lunde LK, Amiry-Moghaddam M, Agre P. Protective role of brain water channel AQP4 in murine cerebral malaria. Proc Natl Acad Sci U S A. 2013;110:1035-40

79. Haj-Yasein NN, Vindedal GF, Eilert-Olsen M, Gundersen GA, Skare O, Laake P, Klungland A, Thoren AE, Burkhardt JM, Ottersen OP, Nagelhus EA. Glialconditional deletion of aquaporin-4 (Aqp4) reduces blood-brain water uptake and confers barrier function on perivascular astrocyte endfeet. Proc Natl Acad Sci U S A. 2011;108:17815-20.

80. Li X, Gao J, Ding J, Hu G, Xiao M. Aquaporin-4 expression contributes to decreases in brain water content during mouse postnatal development. Brain Res Bull. 2013;94:49-55. 
81. Chu H, Xiang J, Wu P, Su J, Ding H, Tang Y, Dong Q. The role of aquaporin 4 in apoptosis after intracerebral hemorrhage. J Neuroinflammation. 2014;11:184.

82. Tang Y, Wu P, Su J, Xiang J, Cai D, Dong Q. Effects of Aquaporin-4 on edema formation following intracerebral hemorrhage. Exp Neurol. 2010;223:485-95.

83. Armulik A, Genove G, Betsholtz C. Pericytes: developmental, physiological, and pathological perspectives, problems, and promises. Dev Cell. 2011;21:193-215.

84. Vanlandewijck M, He L, Mae MA, Andrae J, Ando K, Del Gaudio F, Nahar K, Lebouvier T, Lavina B, Gouveia L, et al. A molecular atlas of cell types and zonation in the brain vasculature. Nature. 2018;554:475-80.

85. Nirwane A, Johnson J, Nguyen B, Miner JH, Yao Y. Mural cell-derived laminin-alpha5 plays a detrimental role in ischemic stroke. Acta Neuropathol Commun. 2019;7:23.

86. Andersen KK, Olsen TS, Dehlendorff C, Kammersgaard LP. Hemorrhagic and ischemic strokes compared: stroke severity, mortality, and risk factors. Stroke. 2009:40:2068-72.

87. Chauhan G, Debette $\mathrm{S}$. Genetic risk factors for ischemic and hemorrhagic stroke. Curr Cardiol Rep. 2016;18:124.

88. Woodruff TM, Thundyil J, Tang SC, Sobey CG, Taylor SM, Arumugam TV. Pathophysiology, treatment, and animal and cellular models of human ischemic stroke. Mol Neurodegener. 2011;6:11.

\section{Publisher's Note}

Springer Nature remains neutral with regard to jurisdictional claims in published maps and institutional affiliations.

Ready to submit your research? Choose BMC and benefit from:

- fast, convenient online submission

- thorough peer review by experienced researchers in your field

- rapid publication on acceptance

- support for research data, including large and complex data types

- gold Open Access which fosters wider collaboration and increased citations

- maximum visibility for your research: over $100 \mathrm{M}$ website views per year

At BMC, research is always in progress.

Learn more biomedcentral.com/submissions 